Situs Jurnal : $\underline{\text { http://ejournal.stiepancasetia.ac.id/index.php/jieb }}$

Jilid 5 Nomor 2 Juli 2019

Hal $238-245$

\title{
PENGARUH KUALITAS PELAYANAN TERHADAP KEPUASAN MASYARAKAT PADA PUSKESMAS RANTAU BADAUH KABUPATEN BARITO KUALA
}

\section{Muhammad Fahmi*}

Abstract: This Research aims to understand about the simultant and partial influence of the services quality which consists of reliability, responsiveness, assurance, emphaty and tangible in against community satisfaction at Health Center of Rantau Badauh Kabupaten Barito The Population of these research are the people who sought services At Health Center of Rantau Badauh Kabupaten Barito Kuala who totaled more than 5.000. While the sample is only 100 people. The instruments that use to collect data are through questionnaires and hypothesis testing which is done by using validity test, reliability test, classic assumption test, multiple linear regression analysis, t-test, f-test, through the help of SPSS version 17. It is concluded that the Quality of service consisting of variable reliability, responsiveness, assurance, emphaty and tangible simultaneously and partially has significant effect on people's satisfaction at Health Center of Rantau Badauh Barito Kuala with emphatic variable has the dominant influence.

Keywords: Reliability, Responsiveness, Assurance, Emphaty, Tangible, Performance

Abstrak: Penelitian ini bertujuan untuk mengetahui pengaruh kualitas pelayanan yang terdiri dari variabel reliability, responsiveness, assurance, emphaty dan tangible secara simultan maupun parsial terhadap kepuasan masyarakat pada Puskesmas Rantau Badauh Kabupaten Barito Kuala. Populasi dalam penelitian ini adalah seluruh masyarakat yang pernah meminta pelayanan pada Puskesmas Rantau Badauh Kabupaten Barito Kuala yang berjumlah lebih dari 5.000 orang, sedangkan sampel yang di ambil sebanyak 100 orang. Instrument pengumpulan data kuesioner dan uji hipotesis dilakukan dengan uji validitas, reliabilitas, uji asumsi klasik, analisis regresi linear berganda, uji t, uji f melalui bantuan program SPSS versi 17. Kesimpulan penelitian ini adalah variabel reliability, responsiveness, assurance, emphaty dan tangible secara simultan maupun parsial berpengaruh signifikan terhadap kepuasan masyarakat pada Puskesmas Rantau Badauh Kabupaten Barito Kuala dengan variabel Emphaty sebagai variabel yang berpengaruh dominan

Kata kunci : Reliability, Responsiveness, Assurance, Emphaty, Tangible, Kinerja

\section{Latar Belakang}

Pelayanan publik sering dilihat sebagai representasi dari eksistensi birokrasi pemerintahan, karena hal itu bersentuhan langsung dengan tuntutan kebutuhan masyarakat. Filosofi dari pelayanan publik menempatkan rakyat sebagai subyek dalam penyelenggaraan pemerintah. Jadi pelayanan publik dapat didefinisikan sebagai suatu proses pemenuhan keinginan dan kebutuhan masyarakat oleh pegawai pemerintah, khususnya instansi yang bertanggung jawab terhadap pelayanan masyarakat.

Salah satu bentuk pelayanan publik yang dilaksanakan oleh pemerintah adalah memenuhi kebutuhan kesehatan masyarakat. Reformasi dibidang kesehatan dilaksanakan untuk 
meningkatkan pelayanan kesehatan dan menjadikannya lebih efisien, efektif serta dapat dijangkau oleh seluruh lapisan masyarakat.

Pusat kesehatan masyarakat (Puskesmas) sebagai salah satu sarana kesehatan yang memberikan pelayanan kesehatan kepada masyarakat memiliki peran yang sangat strategis dalam mempercepat peningkatan derajat kesehatan masyarakat. Oleh karena itu Puskesmas dituntut untuk memberikan pelayanan yang bermutu dan memuaskan bagi masyarakat sesuai standar yang ditetapkan. Seperti yang tertuang dalam Keputusan Menteri Kesehatan Republik Indonesia No. 951/Menkes/SK/Vi/2000 yaitu bahwa 'tujuan pembangunan kesehatan adalah untuk meningkatkan kesadaran, kemauan dan kemampuan hidup sehat bagi setiap orang agar terwujud derajat kesehatan masyarakat yang optimal'. Dengan meningkatnya tingkat pendidikan dan keadaan sosial dalam masyarakat, maka meningkat pula kesadaran akan arti hidup sehat dan keadaan tersebut menyebabkan tuntutan masyarakat akan pelayanan kesehatan yang bermutu.

Puskesmas Rantau Badauh Kabupaten Barito Kuala, sebagai penyedia kesehatan masyarakat wajib untuk memberikan pelayanan publik yang maksimal kepada masyarakat. Pelayanan publik yang diberikan harus secara menyeluruh dengan memberikan pelayanan yang berkualitas agar dapat berimbas pada penilaian dan prespsi publik terhadap kinerja pelayanan puskesmas secara menyeluruh.

Kualitas pelayanan Puskesmas Rantau Badauh Kabupaten Barito Kuala selama ini cukup baik namun perlu ditingkatkan atau diperbaiki seperti kecepatan pelayanan, kecepatan dalam memecahkan masalah, kebersihan ruang pelayanan dan sebagainya. Hal ini bertujuan agar masyarakat semakin merasa puas. Untuk meningkatkan pelayanan yang berkualitas perlu dievaluasi faktor-faktornya, yaitu reliability, responsiveness, assurance, emphaty dan tangible.

Berdasarkan uraian yang telah dikemukakan dalam latar belakang penelitian ini, maka permasalahan yang akan diungkapkan yaitu :

1. Apakah kualitas pelayanan yang terdiri dari variabel reliability, responsiveness, assurance, emphaty dan tangible secara parsial berpengaruh terhadap kepuasan masyarakat pada Puskesmas Rantau Badauh Kabupaten Barito Kuala?

2. Apakah kualitas pelayanan yang terdiri dari variabel reliability, responsiveness, assurance, emphaty dan tangible secara simultan berpengaruh terhadap kepuasan masyarakat pada Puskesmas Rantau Badauh Kabupaten Barito Kuala?

3. Variabel manakah yang berpengaruh dominan terhadap kepuasan masyarakat pada Puskesmas Rantau Badauh Kabupaten Barito Kuala?

\section{Metode Penelitian}

Populasi merupakan wilayah generalisasi yang terdiri atas objek atau subyek yang mempunyai kuantitas dan karakteristik tertentu yang ditetapkan oleh peneliti untuk mempelajari dari penelitian ini adalah seluruh masyarakat yang pernah meminta pelayanan pada Puskesmas Rantau Badauh Kabupaten Barito Kuala yang berjumlah lebih dari 5.000 orang. Sampel merupakan bagian atau sebagian dari populasi yang digunakan sebagai objek penelitian. Sampel penelitian adalah sebanyak 100 orang, dengan waktu selama 4 (empat) bulan. Teknik yang digunakan dengan cara kuesioner (angket) yaitu mengumpulkan data yang diperoleh melalui penyebaran kuesioner. Kuesioner yang digunakan adalah pilihan ganda, dimana setiap item soal diberikan 5 jawaban. Pengukuran variabel menggunakan skala likert yakni didesain untuk menelaah seberapa kuat subjek setuju atau tidak setuju dengan pertanyaan pada skala 5, setiap jawaban responden dari pertanyaan dalam kuesioner diberikan bobot (skor rataan). 

penelitian.

Berikut ini akan dijelaskan mengenai definisi operasional variabel yang digunakan dalam

1. Kualitas Pelayanan (X).

Kualitas Pelayanan merupakan tingkat keunggulan yang diharapkan dan pengendalian atas tingkat keunggulan tersebut untuk memenuhi harapan pelanggan. Indikator-indikatornya adalah sebagai berikut ;

a. Reliability (X.1), yaitu kemampuan untuk memberikan pelayanan sesuai dengan yang dijanjikan secara akurat dan terpercaya.

b. Responsiveness (X.2), yaitu kemampuan untuk membantu dan memberikan pelayanan yang cepat (responsif) dan tepat dengan penyampaian informasi yang jelas.

c. Assurance (X.3), yaitu jaminan atau kepastian untuk menumbuhkan rasa percaya.

d. Emphaty (X.4), yaitu bentuk perhatian yang diberikan dengan berupaya memahami keinginan dan harapan.

e. Tangible (X.5), yaitu kemampuan organisasi dalam menunjukkan eksistensinya kepada pihak eksternal. Penampilan dan kemapanan sarana dan prasarana fisik perusahaan dan keadaan lingkungan sekitarnya adalah bukti nyata dari pelayanan yang diberikan oleh pemberi jasa.

2. Kepuasan Masyarakat (Y).

Kepuasan Masyarakat merupakan tingkat perasaan masyarakat setelah membandingkan kinerja yang ia rasakan dibandingkan dengan harapan.

Metode analisis data yang digunakan adalah regresi linier berganda (multi linier regression method), untuk menganalisis bentuk dan tingkat hubungan antara satu variabel dependen dengan beberapa variabel independen, pengolahan datanya melalui software statistical Package for Social Science (SPSS 17).

\section{Hasil Penelitian dan Pembahasan}

Obyek penelitian yang digunakan dalam penelitian ini diambil dari Puskesmas Rantau Badauh Kabupaten Barito Kuala yang beralamat Jalan Brigjend. Hasan Basri Desa Sungai Gampa Asahi Rt. 10 Kecamatan Rantau Badauh Kabupaten Barito Kuala berdiri tahun 2004. Analisis dimulai dengan melakukan uji multikolinearitas, seperti ditunjukkan pada Tabel 1.

Tabel 1. Multikolinieritas

\begin{tabular}{ccc}
\hline Variabel Bebas & VIF & Keterangan \\
\hline X1 & 9,468 & Tidak terjadi multikolinieritas \\
X2 & 8,781 & Tidak terjadi multikolinieritas \\
X3 & 9,324 & Tidak terjadi multikolinieritas \\
X4 & 8,384 & Tidak terjadi multikolinieritas \\
X5 & 8,336 & Tidak terjadi multikolinieritas \\
\hline
\end{tabular}

Berdasarkan tabel 1, hasil pengujian VIF semuanya di bawah dari 10 sehingga dapat dibuat kesimpulan bahwa data dari kelima variabel yang diteliti tidak ada masalah multikolinieritas.

Langkah selanjutnya adalah analisis regresi berganda, yang menghasilkan persamaan regresi sebagai berikut:

$$
Y=-4,672+0,192\left(X_{1}\right)+0,260\left(X_{2}\right)+0,201\left(X_{3}\right)+0,518\left(X_{4}\right)+0,269\left(X_{5}\right)
$$


Nilai persamaan regresi di atas memiliki nilai koefisien regresi yang positif. Hal ini menunjukkan bahwa variabel-variabel bebas tersebut berbanding lurus atau searah dengan variabel terikatnya. Bila diantara variabel-variabel bebas tersebut ada yang mengalami perubahan (baik naik atau turun), maka variabel terikatnya juga akan berubah ke arah yang sama (naik atau turun). Nilai koefisien regresi yang ditunjukkan dalam persamaan tersebut dapat dijelaskan bahwa ;

1. Nilai a atau konstanta sebesar $-4,672$, artinya jika variabel reliability, responsiveness, assurance, emphaty dan tangible dianggap tetap atau tidak berubah (konstan) maka kepuasan masyarakat adalah sebesar $-4,672$.

2. Nilai $b_{1} x_{1}$ atau koefisien regresi reliability adalah 0,192 , artinya setiap terjadi perubahan satu satuan relialibity akan berpengaruh dalam meningkatkan kepuasan masyarakat sebesar 0,192 dengan asumsi jika variabel responsiveness, assurance, emphaty dan tangible konstan.

3. Nilai $\mathrm{b}_{2} \mathrm{x}_{2}$ atau koefisien regresi responsiveness adalah 0,260 , artinya setiap terjadi perubahan satu satuan responsiveness akan berpengaruh dalam meningkatkan kepuasan masyarakat sebesar 0,260 dengan asumsi jika variabel reliability, assurance, emphaty dan tangible konstan.

4. Nilai $\mathrm{b}_{3} \mathrm{x}_{3}$ atau koefisien regresi assurance adalah 0,201 , artinya setiap terjadi perubahan satu satuan assurance akan berpengaruh dalam meningkatkan kepuasan masyarakat sebesar 0,201 dengan asumsi jika variabel reliability, responsiveness, emphaty dan tangible konstan.

5. Nilai $\mathrm{b}_{4} \mathrm{X}_{4}$ atau koefisien regresi emphaty adalah 0,518 , artinya setiap terjadi perubahan satu satuan emphaty akan berpengaruh dalam meningkatkan kepuasan masyarakat sebesar 0,518 dengan asumsi jika variabel reliability, responsiveness, assurance dan tangible konstan.

6. Nilai $\mathrm{b}_{5} \mathrm{X}_{5}$ atau koefisien regresi tangible adalah 0,269 , artinya setiap terjadi perubahan satu satuan tangible akan berpengaruh dalam meningkatkan kepuasan masyarakat sebesar 0,269 dengan asumsi jika variabel reliability, responsiveness, assurance dan emphaty konstan.

Uji ini digunakan dengan tujuan untuk membuktikan apakah variabel reliability, responsiveness, assurance, emphaty dan tangible berpengaruh secara bersama-sama terhadap kepuasan masyarakat pada Puskesmas Rantau Badauh Kabupaten Barito Kuala.

Berdasarkan hasil perhitungan melalui SPSS menunjukkan Fhitung sebesar 844,596 dan Ftabel dengan menggunakan tingkat signifikasi 5\% serta derajat kebebasan $(\mathrm{df})=(\mathrm{k}-1),(\mathrm{n}-\mathrm{k})$ $=(6-1),(100-6)=2,311$. Hasil tersebut menunjukkan bahwa Fhitung $>$ Ftabel yang berarti variabel reliability, responsiveness, assurance, emphaty dan tangible berpengaruh signifikan secara bersama-sama terhadap kepuasan masyarakat pada Puskesmas Rantau Badauh Kabupaten Barito Kuala. Melalui pengujian ini akan diketahui ada atau tidaknya pengaruh secara parsial antara variabel kualiatas pelayanan terhadap kepuasan masyarakat yaitu dengan cara membandingkan nilai thitung dengan $t_{\text {tabel }}$ pada taraf nyata $5 \%$. Jika nilai $t_{\text {hitung }}>$ nilai $t_{\text {tabel }}$ maka pengaruhnya signifikan.

1. Pengaruh reliability terhadap kepuasan masyarakat pada Puskesmas Rantau Badauh Kabupaten Barito Kuala.

Hasil pengujian hipotesis diketahui nilai $t_{\text {hitung }}=2,474$ sedangkan nilai $t_{\text {tabel }}$ pada level of significant $5 \%(\alpha=0,05)$ adalah 1,985 , maka $t_{\text {hitung }}>t_{\text {tabel }}$ berarti Ho ditolak dan Ha diterima. Artinya terdapat pengaruh yang signifikan secara parsial antara variabel reliability terhadap kepuasan masyarakat pada Puskesmas Rantau Badauh Kabupaten Barito Kuala.

2. Pengaruh responsiveness terhadap kepuasan masyarakat pada Puskesmas Rantau Badauh Kabupaten Barito Kuala.

Hasil pengujian hipotesis diketahui nilai thitung $=4,120$ sedangkan nilai $t_{\text {tabel }}$ pada level of significant $5 \%(\alpha=0,05)$ adalah 1,985 , maka $t_{\text {hitung }}>t_{\text {tabel }}$ berarti Ho ditolak dan Ha diterima. 
Artinya terdapat pengaruh yang signifikan secara parsial antara variabel responsiveness terhadap kepuasan masyarakat pada Puskesmas Rantau Badauh Kabupaten Barito Kuala.

3. Pengaruh assurance terhadap kepuasan masyarakat pada Puskesmas Rantau Badauh Kabupaten Barito Kuala.

Hasil pengujian hipotesis diketahui nilai $t_{\text {hitung }}=3,755$ sedangkan nilai $t_{\text {tabel }}$ pada level of significant 5\% $(\alpha=0,05)$ adalah 1,985 , maka $t_{\text {hitung }}>t_{\text {tabel }}$ berarti Ho ditolak dan Ha diterima. Artinya terdapat pengaruh yang signifikan secara parsial antara variabel assurance terhadap kepuasan masyarakat pada Puskesmas Rantau Badauh Kabupaten Barito Kuala.

4. Pengaruh emphaty terhadap kepuasan masyarakat pada Puskesmas Rantau Badauh Kabupaten Barito Kuala.

Hasil pengujian hipotesis diketahui nilai thitung $=8,021$ sedangkan nilai $t_{\text {tabel }}$ pada level of significant $5 \%(\alpha=0,05)$ adalah 1,985 , maka $t_{\text {hitung }}>t_{\text {tabel }}$ berarti Ho ditolak dan Ha diterima. Artinya terdapat pengaruh yang signifikan secara parsial antara variabel emphaty terhadap kepuasan masyarakat pada Puskesmas Rantau Badauh Kabupaten Barito Kuala.

5. Pengaruh tangible terhadap kepuasan masyarakat pada Puskesmas Rantau Badauh Kabupaten Barito Kuala.

Hasil pengujian hipotesis diketahui nilai thitung $=4,576$ sedangkan nilai $t_{\text {tabel }}$ pada level of significant $5 \%(\alpha=0,05)$ adalah 1,985 , maka $t_{\text {hitung }}>t_{\text {tabel }}$ berarti Ho ditolak dan Ha diterima. Artinya terdapat pengaruh yang signifikan secara parsial antara variabel tangible terhadap kepuasan masyarakat pada Puskesmas Rantau Badauh Kabupaten Barito Kuala.

Berdasarkan hasil output SPSS menunjukkan bahwa nilai tertinggi yang ditunjukkan Standardized Coefficients Beta adalah variabel emphaty yaitu 0,353. Dengan demikian variabel tersebut yang dominan pengaruhnya terhadap kepuasan masyarakat pada Puskesmas Rantau Badauh Kabupaten Barito Kuala.

Berdasarkan tanggapan responden dari hasil kuisioner, umumnya pelaksanaan indikatorindikator dari variabel reliability ini cukup baik namun perlu diperbaiki seperti masalah kedisiplinan dokter dan kecepatan petugas administrasi dalam melayani masyarakat. Selama ini tingkat kedisiplinan dokter dan petugas administrasi sangat kurang. Ketidakdisiplinan tersebut dapat di lihat dari seringnya dokter datang terlambat ke puskesmas dan petugas administrasi sering barada tidak di tempat kerjanya pada saat jam pelayanan. Padahal dalam teorinya, apabila reliability atau keandalan ini dilakukan dengan cepat maka tingkat kepuasan pasti akan meningkat, namun yang terjadi pada Puskesmas Rantau Badauh Kabupaten Barito Kuala, reliability ini malah sebaliknya, dampaknya adalah masyarakat banyak yang mengeluh dan tidak puas akibat dari ketidakdisiplinan dokter dan petugas administrasi, sedangkan tanggapan mengenai prosedur pelayanan dianggap sangat baik oleh masyarakat, hal ini terlihat pada saat pasien datang langsung diarahkan keloket untuk di data, selanjutnya pasien tinggal menunggu waktu giliran untuk berobat.

Responsiveness menyangkut kemauan atau kesiapan para pegawai untuk memberikan pelayanan yang dibutuhkan oleh masyarakat. Umumnya responden juga menilai cukup baik untuk pelaksanaan yang berkaitan dengan responsiveness ini. Namun ada juga sebagian masyarakat yang merasa tidak puas terhadap ketanggapan petugas yang bersangkutan masih belum sepenuhnya mengerti tentang mekanisme sistem kerja dipuskesmas dan dampaknya adalah mereka tidak mampu dalam pengambilan keputusan. Kajian berikutnya adalah masalah kesigapan petugas dalam memberikan pelayanan. Dari hasil penelitian yang diperoleh ternyata masih ada ditemukan petugas yang tidak sigap melayani masyarakat, alasannya mereka adalah 
baru datang dan masih merasa kecapean sehingga tidak dengan segera melayani pasien. Kajian terakhir adalah masalah keikhlasan petugas dalam memberikan bantuan walaupun tidak diminta dalam katagori sedang, hal ini menunjukkan masih adanya hambatan untuk memberikan pelayanan yang prima bagi masyarakat yang membutuhkan pelayanan kesehatan. Kalau tidak mesyarakat itu sendiri yang meminta bantuan jangan harap petugas mau memberikan bantuannya. Seharusnya petugas harus berperan aktif, sigap dalam kondisi apapun untuk membantu secara ikhlas dan tulus dalam melayani masyarakat walaupun tidak diminta.

Assurance berhubungan dengan kemampuan untuk melaksanakan tugas secara spontan yang dapat menunjang kinerja yang baik sehingga menimbulkan kepercayaan dan keyakinan (bebas dari keragu-raguan). Berdasarkan hasil penelitian, Assurance termasuk dalam katagori rendah. Hal ini menunjukkan kinerja pelayanan yang ditujukan oleh variabel ini belum sepenuhnya memberikan kepercayaan dan keyakinan kepada masyarakat seperti halnya tingkat kepercayaan masyarakat terhadap penggunaan obat generik. Padahal obat generik memiliki kualitas yang sama dan cukup baik dengan obat lainnya, hanya saja yang membedakannya adalah sifat obatnya saja. Namun untuk masalah khasiat obat generik mempunyai khasiat yang sama dengan obat jenis lainnya. Tapi fakta yang ditemukan ialah kebanyakan masyarakat belum percaya bahwa obat generik memiliki khasiat yang sama dengan obat lainnya. Mereka masih berpikir mana mungkin ada obat dengan harga yang murah namun memiliki kualitas yang bagus

Variabel emphaty merupakan yang dominan dalam mempengaruhi kepuasan masyarakat Puskesmas Rantau Badauh Kabupaten Barito Kuala. Berdasarkan hasil penelitian yang diperoleh, variabel emphaty masuk dalam katagori rendah. Hal ini berarti banyak petugas Puskesmas Rantau Badauh Kabupaten Barito Kuala yang tidak ramah, tidak sopan, pilih kasih serta tidak sebagai pendengar yang baik apabila masyarakat mempunyai keluhan. Tentunya hal ini harus diperbaiki oleh penyelenggara pelayanan seperti bersikap ramah, tidak pilih kasih, tidak memandang status sosial dan juga sebagai pendengar yang baik bagi masyarakat yang mempunyai keluhan. Apabila pelayanan yang diberikan tidak ramah dan selalu pilih kasih, tentunya hal ini akan mencerminkan betapa lemahnya posisi masyarakat sebagi penerima jasa pelayanan. Walaupun hanya sebagian petugas tetapi dampaknya bisa merusak citra atau nama baik puskesmas itu sendiri. Ketidakramahan dan ketidaksopanan pegawai tersebut dilihat dari cara berkomunikasi pegawai dengan masyarakat, berbicara sambil menerima telepon, kadangkadang merokok sambil memberikan pelayanan serta menggunakan sandal dan berpakaian bebas. Akibat dari itu semua, masyarakat banyak yang merasa bahwa diri mereka dianggap remeh walaupun hanya sekedar berbincang-bincang untuk menyampaikan keluhan mereka masing-masing.

Variabel tangible pada Puskesmas Rantau Badauh Kabupaten Barito Kuala termasuk dalam katagori sedang. Hal ini berarti bukti langsung pelayanan pada Puskesmas Rantau Badauh Kabupaten Barito Kuala cukup baik untuk itu juga perlu dibenahi terutama kebersihan ruang pelayanan, toilet dan kamar mandi.

Mengenai tingkat kepuasan masyarakat terhadap pelayanan petugas Puskesmas Rantau Badauh Kabupaten Barito Kuala tergolong rendah. Hal ini menunjukkan bahwa masyarakat tidak merasa puas, tidak senang dan tidak sesuai harapan mereka. Hal itu tentunya harus diperbaiki karena dinamika tuntutan masyarakat yang demikian cepat berubah, harus diimbangi dengan kecepatan perubahan pola kerja dan tindakan pelayanan petugas kesehatan pula, hal ini berarti setiap masyarakat mengharapkan kinerja petugas kesehatan sesuai normatifnya yaitu lebih berfokus pada aspek yang berkaitan dengan dimensi pelayanan. Kedepannya diharapkan petugas kesehatan ini harus lebih mengutamakan pelayanan yang prima lagi kepada pasien sesuai dengan kode etik dari mereka masing-masing. 


\section{Kesimpulan}

Berdasarkan pada serangkaian pembahasan yang telah dikemukakan dari hasil penelitian ini, dapat dibuat kesimpulan sebagai berikut:

1. Kualitas pelayanan yang terdiri dari variabel reliability, responsiveness, assurance, emphaty dan tangible secara parsial berpengaruh signifikan terhadap kepuasan mesayarakat pada Puskesmas Rantau Badauh Kabupaten Barito Kuala.

2. Kualitas pelayanan yang terdiri dari variabel reliability, responsiveness, assurance, emphaty dan tangible secara simultan berpengaruh signifikan terhadap kepuasan masyarakat pada Puskesmas Rantau Badauh Kabupaten Barito Kuala.

3. Emphaty variabel yang berpengaruh dominan terhadap kepuasan masyarakat pada Puskesmas Rantau Badauh Kabupaten Barito Kuala.

Dari hasil penelitian ini yang telah dikemukakan pada pembahasan dan kesimpulan, dapat disusun saran-saran sebagai berikut:

1. Lebih mengutamakan pelayanan yang prima sesuai dengan kode etik dari mereka masingmasing yaitu melayani dan memberikan yang terbaik bagi masyarakat karena pegawai di Puskesmas adalah abdi negera yang tugasnya mengabdikan diri kepada masyarakat, paling tidak petugas harus belajar ramah, sopan, on time, belajar senyum, harus sigap, dan tidak memandang status sosial.

2. Pegawai harus menguasai mekanisme sistem kerja di Puskesmas agar jangan sampai saling melempar tugas dan tanggung jawab.

3. Perlu dilakukan perekrutan tenaga khusus untuk mengelola kebersihan ruang pelayanan.

\section{DAFTAR PUSTAKA}

Burhan, Bungin, 2009 Metodelogi Penelitian Kuantitatif, Edisi Pertama. Penerbit: Kencana Prenada Media Group, Jakarta

Gujarati, Damodar, 2005, Ekonometrika Dasar, Penerbit : Erlangga, Jakarta

Irawan, Handi, 2008, Membedah Strategi Kepuasan pelanggan, Cetakan pertama, PT. Gramedia, Jakarta.

Keputusan Menteri Pendayagunaan Aparatur Negara Nomor : Kep/16/M.PAN/2/2014 Tentang survey Kepuasan Masyarakat.

Koller, Philip, 2006 Manajemen Pemasaran, Penerbit : Erlangga Jakarta.

Mardalis, 2006, Metode Penelitian (Suatu Pendekatan Proposal), Penerbit : Bumi Akasara, Jakarta.

Mutaqin, Ahmad, 2006, Pengaruh Kualitas Pelayanan dan Fasilitas Terhadap Kepuasan Pelanggan Bus PO, Timbul Jaya di Wonogiri. Jurusan Ekonomi Fakultas Ekonomi Universitas Negeri Semarang.

Nachrowi, H, 2005, Manajemen Strategik Organisasi Non Profit Bidang Pemerintahan Gajah Mada University Press, Yogyakarta.

Nawari, 2010, Analisis Regresi dengan MS Excel 2007 dan SPSS 17, Penerbit PT. Elex Media Komputindijo, Jakarta.

Notoatmodjo, Soekidjo, 2005, Metodelogi Penelitian Kesehatan, Penerbit : Salemba, Jakarta.

Prasetyo Adi, Analisis Pengaruh Kualitas Pelayanan Terhadap Kepuasan Nasabah Bmt Kaffah Yogyakarta, Program Studi Manajemen Syariah Pada Jurusan Ekonomi Islam STAIN Surakarta.

Sarwoko, 2005 Dasar-dasar Ekonometrika, Penerbit : Andi Offset, Yogyakarta.

Sasmita, Rochiman, 2006, Metodelogi Penelitian, Penerbit : Mahardika Group Surabaya.

Sugiyono, 2006 Statistika untuk Penelitian, Penerbit : CV. Alfa Beta, Bandung.

Sulistyo, B. 2009, Pelayanan Publik, Penerbit : Erlangga, Jakarta. 
Tjiptono, Fandy, 2005, Strategi Pemasaran, Penerbit : Andi Offset, Yogyakarta.

Umar, H. 2007, Riset Sumber Daya Manusia dalam Organisasi, Penerbit : Gramedia, Jakarta. Wursanto, 2012, Manajemen Kepegawaian, Kanisius, Yogyakarta. 